Pacific Journal of Mathematics

THE BERGMAN KERNEL FUNCTION FOR TUBES OVER
CONVEX CONES 


\title{
THE BERGMAN KERNEL FUNCTION FOR TUBES OVER CONVEX CONES
}

\author{
ADAM KORÁNYI
}

In this article we determine the Bergman kernel function of the tube domain over an arbitrary convex cone not containing any entire straight line. For homogeneous self-dual cones this problem was solved by O. S. Rothaus ([3], Theorem 2.6). It turns out that his method can also be used in our considerably more general case. In fact, the proofs of our Theorems 1 and 2 follow closely the corresponding proofs of Rothaus; it is only in Lemma 2 that the proof of Rothaus has to be replaced by an essentially different convexity argument.

Let $V$ be an $n$-dimensional real vector space. A set $D \subset V$ is called a cone if $x \in D$ and $\lambda>0$ imply $\lambda x \in D$. Let $V^{*}$ be the dual space of $V$. The dual cone $D^{*}$ of $D$ is defined as the set of all $\alpha \in V^{*}$ such that $\langle\alpha, x\rangle>0$ for all $x \in \bar{D}, x \neq 0$. We call the cone $D$ regular if it is

(i) open,

(ii) convex,

(iii) nonempty, and

(iv) contains no entire straight line, i.e. $x \in D$ implies $-x \notin D$. It is easy to see that if $D$ is regular then $D^{*}$ is regular too, and $D^{* *}=D$.

We assume that a Euclidean norm $x \rightarrow|x|$ is defined on $V$. The dual norm on $V^{*}$ will likewise be denoted by $\alpha \rightarrow|\alpha|$.

Lemma 1. If $D$ is a regular cone and $K \subset D$ is a compact set then there exists a number $\rho>0$ such that $\langle\alpha, x\rangle \geqq \rho|\alpha|$ for all $x \in K, \alpha \in \bar{D}^{*}$.

Proof. The proof is the same as that of [2] Lemma 1. By homogeneity it suffices to prove the assertion for $|\alpha|=1$. Let $S=$ $\left\{\alpha \in V^{*}|| \alpha \mid=1\right\}$ be the unit sphere in $V^{*}$. Now $\langle\alpha, x\rangle$ is a positive continuous function on the compact set $\left(S \cap \bar{D}^{*}\right) \times K$ and thus has a positive minimum $\rho$, finishing the proof.

We define the positive real-valued function $M$ on $D^{*}$ by

$$
M(\alpha)=\int_{D} e^{-\langle\alpha, x\rangle} d x
$$

for all $\alpha \in D^{*}$. By Lemma 1 the integral converges uniformly on compact sets. As it can immediately be seen, $M$ is a homogeneous function of degree $-n$.

Lemma 2. Let $D$ be a regular cone and let $\beta \in \partial D^{*}$ (the boundary of $D^{*}$ in $\left.V^{*}\right)$. Then

Received May 4, 1962. 


$$
\lim _{\alpha \rightarrow \beta} M(\alpha)=\infty
$$

Proof. If $\beta=0$ the assertion is trivial. Let $\beta \neq 0$. For $\alpha \in D^{*}$ and $t>0$ define $H_{\alpha}(t)=\{x \in D \mid\langle\alpha, x\rangle=t\}$ and let

$$
V_{\alpha}(t)=\int_{H_{\alpha}(t)} d v_{\alpha}
$$

be the volume of $H_{\alpha}(t)$ ( $d v_{\alpha}$ denotes the volume element of the hyperplane $\{x \mid\langle\alpha, x\rangle=t\})$. Clearly we have $V_{\alpha}(t)=t^{n-1} V_{\alpha}(1)$ for all $t>0$. Also

$$
\begin{aligned}
M(\alpha) & =\int_{D} e^{-\langle\alpha, x\rangle} d x=\int_{0}^{\infty} d t \int_{B_{\left.\alpha^{(}\right)}(t)} e^{-\langle\alpha, x\rangle} d v_{\alpha} \\
& =\int_{0}^{\infty} V_{\alpha}(t) e^{-t} d t=V_{\alpha}(1) \Gamma(n) .
\end{aligned}
$$

Therefore the Lemma will be proved if we show that $\lim _{\alpha \rightarrow \beta} V_{\alpha}(1)=\infty$.

Let $U \subset \bar{D}^{*}$ be a compact neighborhood of $\beta$ relative to $\bar{D}^{*}$. Then the set $L$ of all $x \in D$ such that $\langle\alpha, x\rangle<1$ for all $\alpha \in U$ has an interior. (In fact, if $A$ is a bound for $|\alpha|$ on $U$, it is easy to see that $L$ contains all $x \in D$ such that $\left.|x|<A^{-1}\right)$. Let $K$ be an open sphere contained in $L$; let $c \in D$ be its center and $r>0$ its radius.

For $\alpha \in U$ let $K_{\alpha}$ be the $(n-1)$-dimensional sphere of radius $r$ and center $c_{\alpha}=\langle\alpha, c\rangle^{-1} c$ contained in the hyperplane $\{x \mid\langle\alpha, x\rangle=1\}$. By convexity and by $\left.\langle\alpha, c\rangle^{-1}\right\rangle 1$ we have $K_{\alpha} \subset H_{\alpha}(1)$. Since $\left|c_{\alpha}\right|=\langle\alpha, c\rangle^{-1}|c|$ and since the continuous function $\langle\alpha, c\rangle^{-1}$ is bounded on the compact set $U$, there exists a number $R$ such that

$$
\left|c_{\alpha}\right| \leqq R
$$

for all $\alpha \in U$.

Now let $\Omega>R$ be an arbitrarily large number. There exists an element $a \in \bar{D},|a|=1$ such that $\langle\beta, a\rangle=0$, for otherwise we would have $\beta \in D^{*}$. Hence there exists an element $x \in D,|x|=1$ such that $\langle\beta, x\rangle\left\langle(R+\Omega)^{-1}\right.$. It follows then that there exists a neighborhood $U(\Omega) \subset U$ of $\beta$ relative to $D^{*}$ such that $\langle\alpha, x\rangle\left\langle(R+\Omega)^{-1}\right.$ for all $\alpha \in U(\Omega)$. Let $x_{\alpha}=\langle\alpha, x\rangle^{-1} x$. Clearly we have $x_{\alpha} \in H_{\alpha}(1)$ and

$$
\left|x_{\alpha}\right|>R+\Omega
$$

for all $\alpha \in U(\Omega)$. Now $H_{\alpha}(1)$ is convex, and thus contains the convex hull $B_{\alpha}$ of $K_{\alpha}$ and $x_{\alpha}$; hence, be (1) and (2),

$$
V_{\alpha}(1) \geqq \int_{B_{\alpha}} d v_{\alpha}>\frac{C}{n-2} \Omega
$$

for all $\alpha \in U(\Omega), C$ denoting the volume of the $(n-2)$-dimensional sphere of radius $r$. This completes the proof. 
Let $V_{\sigma}=V \oplus i V$ be the complexification of $V$. The tube over $D$ in $V_{o}$ is the domain $T_{D}=\{x+i y \mid x \in D, y \in V\}$. For $z=x+i y \in V_{o}$ and $\alpha \in V^{*}$ we write $\langle\alpha, z\rangle=\langle\alpha, x\rangle+i\langle\alpha, y\rangle$. We denote by $\mathscr{L}^{2}\left(T_{D}\right)$ the Hilbert space of holomorphic functions on $T_{D}$, square integrable with respect to $d x d y$, and by $L_{M I}^{2}\left(D^{*}\right)$ the Hilbert space of functions on $D^{*}$ square integrable with respect to $M(\alpha) d \alpha$.

THEOREM 1. The mapping $\varphi \rightarrow f$ defined by

$$
f(z)=\pi^{-n / 2} \int_{D^{*}} \varphi(\alpha) e^{-\langle\alpha, z\rangle} d \alpha
$$

is an isomorphism of $L_{M}^{2}\left(D^{*}\right)$ onto $\mathscr{L}^{2}\left(T_{D}\right)$.

Proof. Let $\varphi \in L_{M}^{2}\left(D^{*}\right)$. Then

$$
\begin{aligned}
& \int_{D^{*}}\left|\varphi(\alpha) e^{-\langle\alpha, z\rangle}\right| d \alpha=\int_{D^{*}}|\varphi(\alpha)| e^{-\langle\alpha, x\rangle} d \alpha \\
& \quad \leqq\left(\int_{D^{*}}|\varphi(\alpha)|^{2} M(\alpha) d \alpha\right)^{1 / 2}\left(\int_{D^{*}} e^{-2\langle\alpha, \alpha\rangle} M(\alpha)^{-1} d \alpha\right)^{1 / 2}
\end{aligned}
$$

by the Schwarz inequality. The first integral is just $\|\varphi\|^{2}$, the second is also convergent by Lemma 2 and by the homogeneity of $M$; by Lemma 1 it is even bounded on compact subsets of $D$. Thus (3) converges absolutely and uniformly on compact subsets of $T_{D}$, and hence represents a holomorphic function. Furthermore, reversing the order of integration (which is possible since the integrand is positive and measurable), and then applying the Plancherel theorem we have

$$
\begin{aligned}
\|\varphi\|^{2} & =\int_{D^{*}}|\varphi(\alpha)|^{2} M(\alpha) d \alpha=\int_{D^{*}}|\varphi(\alpha)|^{2} d \alpha \int_{D} e^{-\langle\alpha, x\rangle} d x \\
& =2^{n} \int_{D^{*}}|\varphi(\alpha)|^{2} d \alpha \int_{D} e^{-2\langle\alpha, x\rangle} d x=2^{n} \int d x \int_{D^{*}}\left|\varphi(\alpha) e^{-\langle\alpha, x\rangle}\right|^{2} d \alpha \\
& =\int_{D} d x \int_{V}|f(x+i y)|^{2} d y=\|f\|^{2},
\end{aligned}
$$

which shows that $f \in \mathscr{L}^{2}\left(T_{D}\right)$ and also that the mapping is an isomorphism.

Remains to show (and this is the more important part) that the isomorphism is onto.

First we prove that there exists a measurable function $\varphi$ on $V^{*}$ such that

$$
f(z)=f(x+i y)=\lim \pi^{-n / 2} \int_{V^{*}} \varphi(\alpha) e^{-\langle\alpha, z\rangle} d \alpha
$$

for almost all $x \in D$. In fact, by Fubini's theorem $f(x+i y)$ as a function of $y$ is in $L^{2}(V)$ for almost all $x$; so the Fourier transform 


$$
\psi(x, \alpha)=\lim \pi^{-n / 2} \int_{V} f(x+i y) e^{-i\langle\alpha, y\rangle} d y
$$

exists. The assertion is that $\psi(x, \alpha)=\varphi(\alpha) e^{-\langle\alpha, x\rangle}$ with some measurable $\varphi$. Let $N \subset D$ be a subset whose distance from $\partial D$ is $d>0$. Then, by a well-known property of $\mathscr{L}^{2}$-spaces, $|f(z)|=|f(x+i y)| \leqq C_{a}\|f\|$ for all $x \in N, f \in \mathscr{L}^{2}\left(T_{D}\right)$. Using this remark the proof of our assertion is the same as that of a similar assertion in [1], p. 128, and will not be reproduced here.

Next we show that $\varphi(\alpha)=0$ for almost all $\alpha \notin D^{*}$. In fact, using the Plancherel theorem and reversing the order of integration we obtain

$$
\|f\|^{2}=2^{n} \int_{V^{*}} d \alpha \int_{D}|\varphi(\alpha)|^{2} e^{-2\langle\alpha, x\rangle} d x .
$$

In particular, $\int_{D}|\varphi(\alpha)|^{2} e^{-2\langle\alpha, x\rangle} d x$ exists for almost all $\alpha$ and is integrable. Now if $\alpha \notin D^{*}$, then $\langle\alpha, x\rangle<0$ for some $x \in D$ and hence $\int_{D} e^{-2\langle\alpha, x\rangle} d x$ diverges. Therefore $\varphi(\alpha)=0$ for almost all such $\alpha$.

Finally we must show that $\varphi \in L_{M}^{2}\left(D^{*}\right)$. This however follows at once from the Plancherel theorem through the equalities (4).

THeOREM 2. The Bergman kernel function of $T_{D}$ is

$$
K(z, w)=\frac{1}{\pi^{n}} \int_{D^{*}} e^{-\langle\alpha, z+\bar{w}\rangle} M(\alpha)^{-1} d \alpha
$$

Proof. From Theorem 1 it is clear that, for fixed $w \in T_{D}, K(z, w)$ as a function of $z$ is in $\mathscr{L}^{2}\left(T_{D}\right)$. Also for fixed $w \in T_{D}$ and $x \in D, K(z, w)$ is in $L^{2}(V)$ as a function of $y$.

Let $f \in \mathscr{L}^{2}\left(T_{D}\right)$, then $f$ can be represented in the form (3). Using the Plancherel theorem and then reversing the order of integration (which can be done since the integrand is measurable and the repeated integral in reverse order exists absolutely), we obtain

$$
\begin{aligned}
\int_{T^{\prime}} f(z) \bar{K} & (z, w) d x d y=\int_{D} d x \int_{V} f(z) \bar{K}(z, w) d y \\
& =2^{n} \int_{D} d x \int_{V^{*}} \varphi(\alpha) e^{-\langle\alpha, x\rangle} e^{-\langle\alpha, x+w\rangle} M(\alpha)^{-1} d \alpha \\
& =2^{n} \int_{V^{*}} d \alpha \varphi(\alpha) e^{-\langle\alpha, w\rangle} M(\alpha)^{-1} \int_{D} e^{-2\langle\alpha, x\rangle} d x \\
& =\int_{V^{*}} \varphi(\alpha) e^{-\langle\alpha, w\rangle} d \alpha=f(w)
\end{aligned}
$$

for all $w \in T_{D}$. Owing to the fact that the Bergman kernel is uniquely determined by its reproducing property, the proof is finished. 
THE BERGMAN KERNEL FUNCTION FOR TUBES OVER CONVEX CONES 1359

\section{REFERENCES}

1. S. Bochner and W. T. Martin, Several Complex Variables, Princeton University Press, 1948.

2. M. Koecher, Positivitätsbereiche im $R^{n}$, Amer. J. Math., 79 (1957), 575-596.

3. O. S. Rothaus, Domains of Positivity, Abh. Math. Semin. Hamburg 24 (1960), 189-235.

UNIVERSity of CALIFORNIA, BERKELEy 



\section{PACIFIC JOURNAL OF MATHEMATICS}

\section{EDITORS}

\author{
Ralph S. Phillips \\ Stanford University \\ Stanford, California \\ M. G. Arsove \\ University of Washington \\ Seattle 5 , Washington
}

\author{
A. L. Whiteman \\ University of Southern California \\ Los Angeles 7, California \\ Lowell J. Paige \\ University of California \\ Los Angeles 24, California
}
E. F. BECKENBACH
D. DERRY
ASSOCIATE EDITORS
T. M. CHERRY
M. OHTSUKA
H. L. ROYDEN
E. G. STRAUS
E. SPANIER
F. WOLF

\section{SUPPORTING INSTITUTIONS}

\author{
UNIVERSITY OF BRITISH COLUMBIA \\ CALIFORNIA INSTITUTE OF TECHNOLOGY \\ UNIVERSITY OF CALIFORNIA \\ MONTANA STATE UNIVERSITY \\ UNIVERSITY OF NEVADA \\ NEW MEXICO STATE UNIVERSITY \\ OREGON STATE UNIVERSITY \\ UNIVERSITY OF OREGON \\ OSAKA UNIVERSITY \\ UNIVERSITY OF SOUTHERN CALIFORNIA
}

\author{
STANFORD UNIVERSITY \\ UNIVERSITY OF TOKYO \\ UNIVERSITY OF UTAH \\ WASHINGTON STATE UNIVERSITY \\ UNIVERSITY OF WASHINGTON \\ AMERICAN MATHEMATICAL SOCIETY \\ CALIFORNIA RESEARCH CORPORATION \\ SPACE TECHNOLOGY LABORATORIES \\ NAVAL ORDNANCE TEST STATION
}

Mathematical papers intended for publication in the Pacific Journal of Mathematıcs should be typewritten (double spaced), and the author should keep a complete copy. Manuscripts may be sent to any one of the four editors. All other communications to the editors should be addressed to the managing editor, L. J. Paige at the University of California, Los Angeles 24, California.

50 reprints per author of each article are furnished free of charge; additional copies may be obtained at cost in multiples of 50 .

The Pacific Journal of Mathematics is published quarterly, in March, June, September, and December. Effective with Volume 13 the price per volume (4 numbers) is $\$ 18.00$; single issues, $\$ 5.00$. Special price for current issues to individual faculty members of supporting institutions and to individual members of the American Mathematical Society: $\$ 8.00$ per volume; single issues $\$ 2.50$. Back numbers are available.

Subscriptions, orders for back numbers, and changes of address should be sent to Pacific Journal of Mathematics, 103 Highland Boulevard, Berkeley 8, California.

Printed at Kokusai Bunken Insatsusha (International Academic Printing Co., Ltd.), No. 6, 2-chome, Fujimi-cho, Chiyoda-ku, Tokyo, Japan.

PUBLISHED BY PACIFIC JOURNAL OF MATHEMATICS, A NON-PROFIT CORPORATION

The Supporting Institutions listed above contribute to the cost of publication of this Journal, but they are not owners or publishers and have no responsibility for its content or policies. 


\section{Pacific Journal of Mathematics}

\section{Vol. 12 , No. 4 \\ April, 1962}

Tsuyoshi Andô, On fundamental properties of a Banach space with a cone ..... . 1163

Sterling K. Berberian, A note on hyponormal operators ................ 1171

Errett Albert Bishop, Analytic functions with values in a Frechet space . . . . . . . 1177

(Sherman) Elwood Bohn, Equicontinuity of solutions of a quasi-linear equation ............................................ 1193

Andrew Michael Bruckner and E. Ostrow, Some function classes related to the class of convex functions . . . . . . . . . . . . . . . . . . . . . . . . 1203

J. H. Curtiss, Limits and bounds for divided differences on a Jordan curve in the complex domain . . ................................. 1217

P. H. Doyle, III and John Gilbert Hocking, Dimensional invertibility . . . . . . . . 1235

David G. Feingold and Richard Steven Varga, Block diagonally dominant matrices and generalizations of the Gerschgorin circle theorem ................. 1241

Leonard Dubois Fountain and Lloyd Kenneth Jackson, A generalized solution of the boundary value problem for $y^{\prime \prime}=f\left(x, y, y^{\prime}\right) \ldots \ldots \ldots \ldots \ldots \ldots \ldots \ldots \ldots$

Robert William Gilmer, Jr., Rings in which semi-primary ideals are primary. . . . . 1273

Ruth Goodman, K-polar polynomials .......................... 1277

Israel Halperin and Maria Wonenburger, On the additivity of lattice completeness ........................................... 1289

Robert Winship Heath, Arc-wise connectedness in semi-metric spaces . . . . . . . . 1301

Isidore Heller and Alan Jerome Hoffman, On unimodular matrices . . . . . . . . . . . 1321

Robert G. Heyneman, Duality in general ergodic theory . . . . . . . . . . . . . . . 1329

Charles Ray Hobby, Abelian subgroups of p-groups . . . . . . . . . . . . . . . 1343

Kenneth Myron Hoffman and Hugo Rossi, The minimum boundary for an analytic

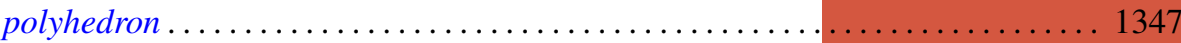

Adam Koranyi, The Bergman kernel function for tubes over convex cones ........ 1355

Pesi Rustom Masani and Jack Max Robertson, The time-domain analysis of a continuous parameter weakly stationary stochastic proces.

William Schumacher Massey, Non-existence of almost-complex structures on

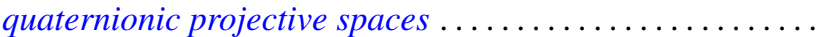

Deane Montgomery and Chung-Tao Yang, A theorem on the action of $\mathrm{SO}(3) \ldots . .1385$

Ronald John Nunke, A note on Abelian group extensions . . . . . . . . . . . . . 1401

Carl Mark Pearcy, A complete set of unitary invariants for operators generating finite $W^{*}$-algebras of type $I$

Edward C. Posner, Integral closure of rings of solutions of linear differential equations.

Duane Sather, Asymptotics. III. Stationary phase for two parameters with an application to Bessel functions.

J. Śladkowska, Bounds of analytic functions of two complex variables in domains

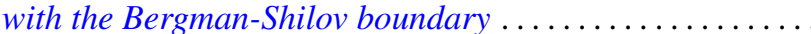

Joseph Gail Stampfli, Hyponormal operators .

George Gustave Weill, Some extremal properties of linear combinations of kernels

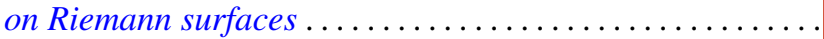

